$$
\begin{aligned}
& \text { تأثير شش هفته تمرين قدرتى با تراباند بر برخى متغير هاى توان بىهوازى بسكتباليستهاى جوان } \\
& \text { محمود خدابخشى'، احمد ابراهيمى عطرى'، سيدعلى اكبر هاشمى جواهرى'، حسين عاشورى؟، ناصر فرخروّ، وحيد خدابندهلوه }
\end{aligned}
$$

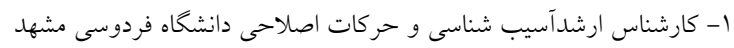

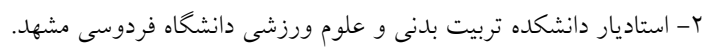

$$
\begin{aligned}
& \text { r- هئيت علمى دانشخاه بيام نور رزن. } \\
& \text { F- كارشناس ارشد آسيب شناسى و حركات اصلاحى دانشكاه رازى كرمانشاه. } \\
& \text { ه- دانشجوى كارشناسى ارشد تربيت بدنى دانشگاه آزاد بروجرد. }
\end{aligned}
$$

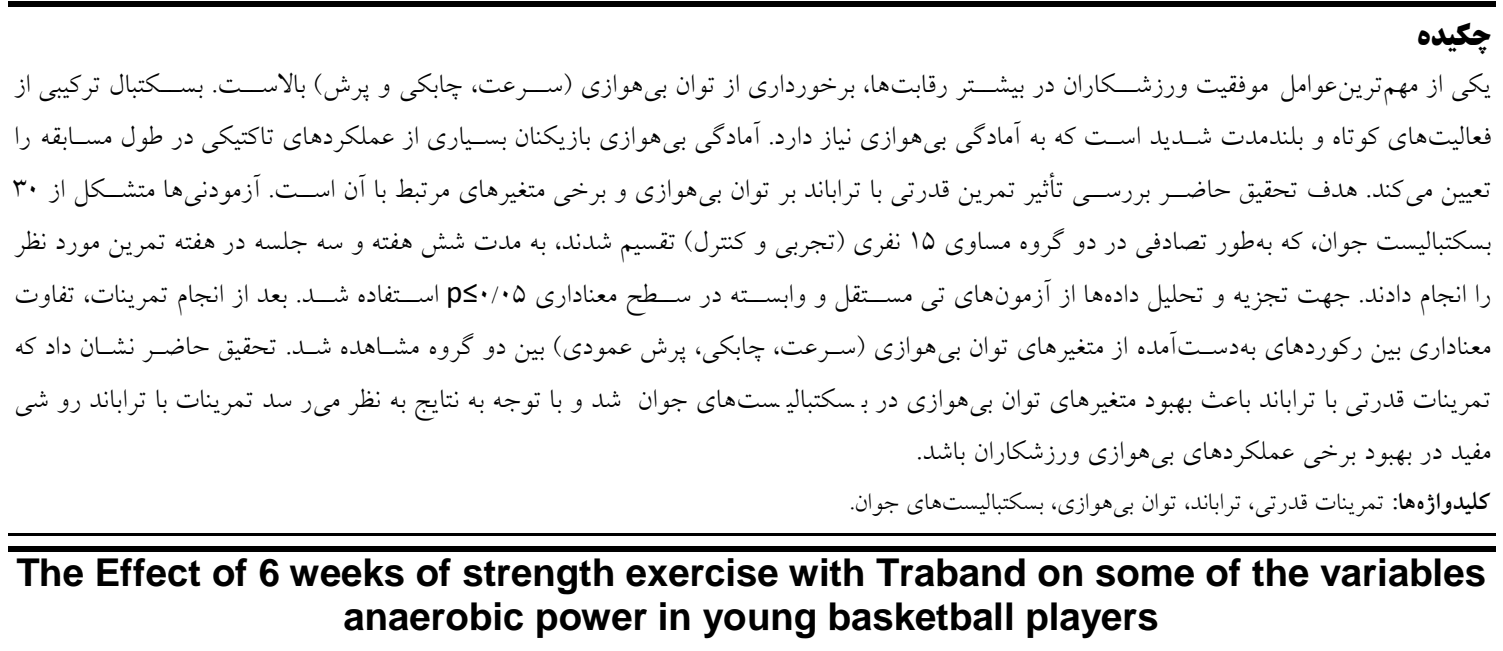

\section{The Effect of 6 weeks of strength exercise with Traband on some of the variables anaerobic power in young basketball players}

\author{
khodabakhshi.M. ${ }^{1}$., Ebrahimi Atri A. ${ }^{2}$., Hashemi Javaheri.S. A. ${ }^{2}$., ashouri.H. ${ }^{3}$., , farookhro.N. ${ }^{4}$.,, \\ khodabandelo.V. ${ }^{5}$ \\ 1- MSc in Physical Education and Sport Sciences, Ferdowsi University, Mashhad, Iran \\ 2- Assistant professor and faculty, physical education and sport science, Ferdowsi University of Mashhad, Iran. \\ 3- Payame Noor university science association. \\ 4- MSc in Physical Education and Sport Sciences, Razi University, Kermanshahe, Iran. \\ 5- Graduate student, physical education and sport science, Borujerd University.
}

\title{
Abstract
}

One of the most important success factors in most athletic competitions, receiving aerobic power (speed, agility and jumping) high. Basketball is a great combination of short and long term activities that depend on aerobic fitness. Anaerobic fitness of many players during the match determines tactical the performance. The purpose of the present study to investigate the effects of strength exercises on anaerobic power and some the variables related Traband it. The subjects consisted of 30 basketball players Young, randomly into two equal groups of 15 subjects (experimental and control) were randomly assigned to 6 weeks and 3 sessions the Exercises were done in a week. To analyze the data, independent samples T-test and paired sample T-test used at a significance level $p \leq 0 / 05$. Later for six weeks of exercises, significant differences between the records obtained from the anaerobic power the variables (speed, agility, vertical jump) were observed between the two groups. The present study showed that the strength exercises with the variables Traband improve anaerobic power in young basketball players and And according to the results of seem to exercises Traband useful method for improving performance of the anaerobic the athletes.

Keywords: strength exercises, Traband, anaerobic power, young basketball player. 
كارآيى تمرين ورزشـى به شـدت و حجم، زمان و تواتر تمرين و توانايى ورزشـكار بسـتخى دارد؛ بنابراين

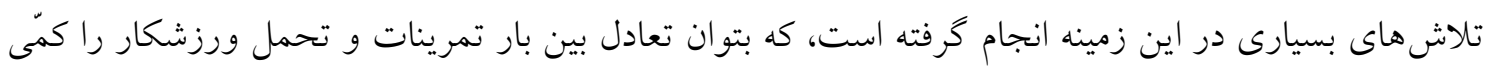

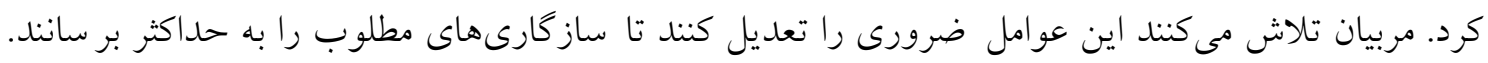
از طرف ديخر، ورزشــكار اغلب به برنامه تمرينى براى رســيدن به حداكثر آمادگى در يكى دوره زمانى كوتاه

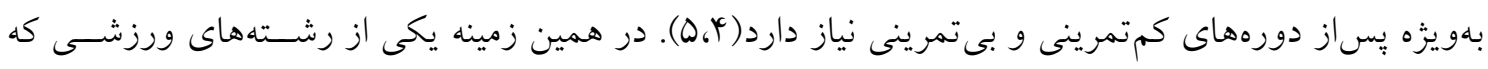

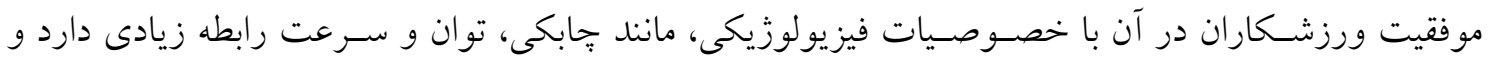

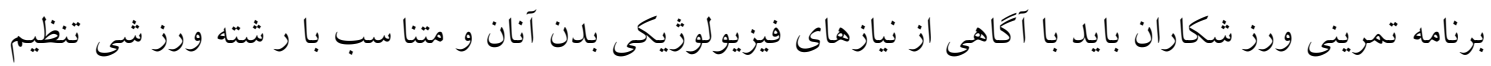

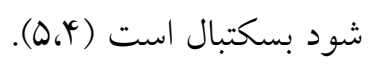

بازى بسـكتبال با حركت و جابهجايى دائمى و مداوم انجام مىشـود. انتقال روان و يكنواخت از دفاع به حمله در اين ورزش وجود دارد و تمام بازيكنان حركات مشـابهى (مثل ريباند و شـوتكردن) را در زمين

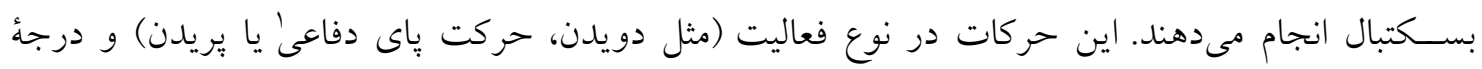

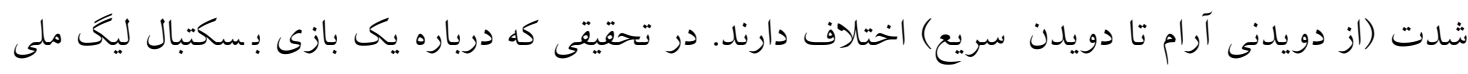

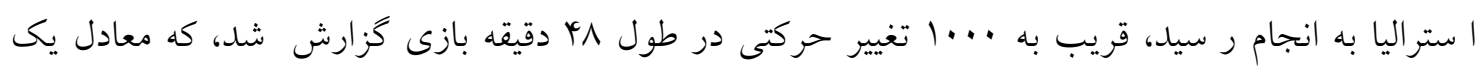

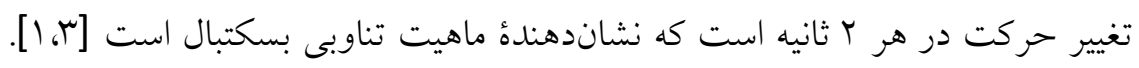

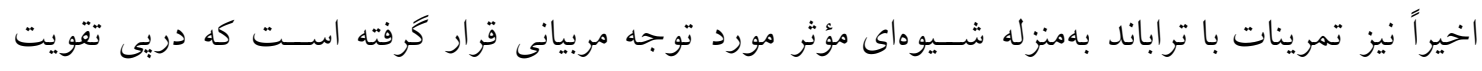

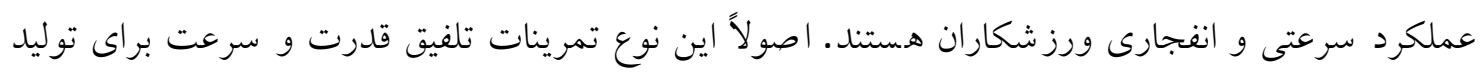
توان است. اين تمرينات با دركيركردن تعداد بيشترى از تارهاى عضلانى در اثر فعالشدن دوكهاى عضلانى

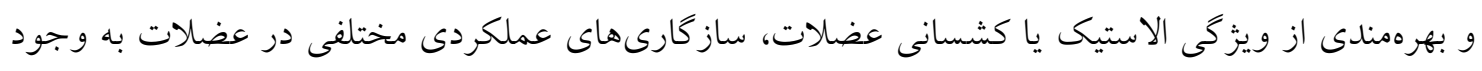

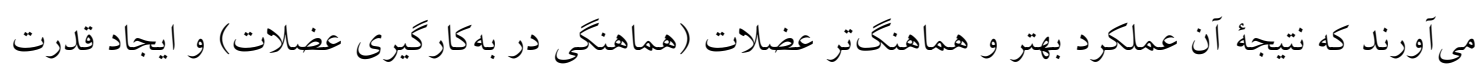

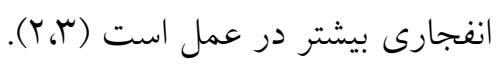

براساس يافتها، در ورزش بسكتبال به تمرينات خاص براى هر دو سيستم بىهوازى (بدون لاكتيك/ لاكتيك)

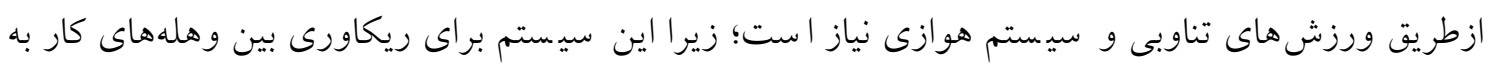

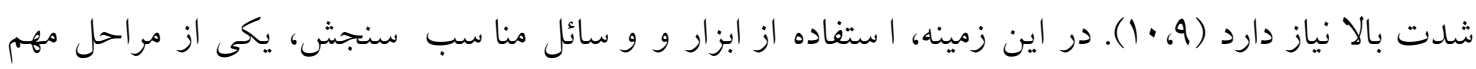

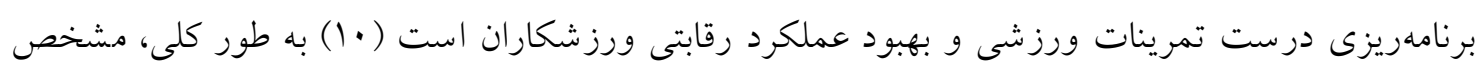

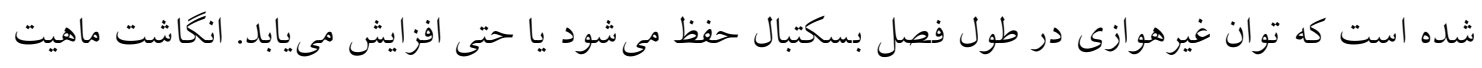

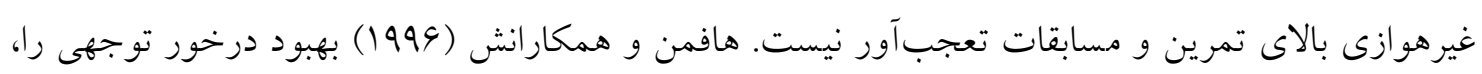

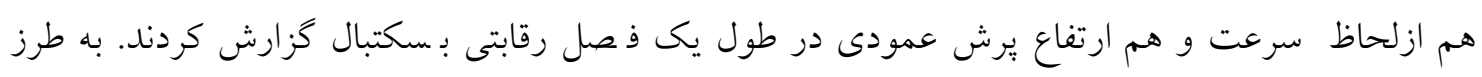

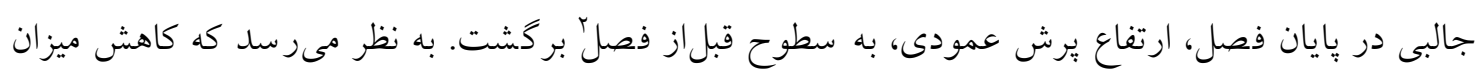


يرش با بديدة بيشتمرين در ارتباط باشد. تصور بر آن است كه اين اجزاى آمادگى (سرعت و ارتفاع برش

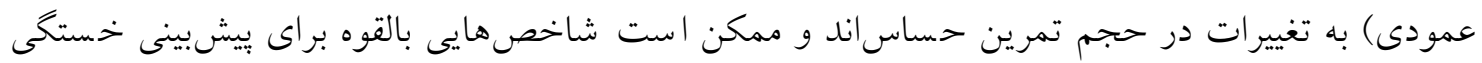
در بازيكنان بسكتبال باشند (rابrا).

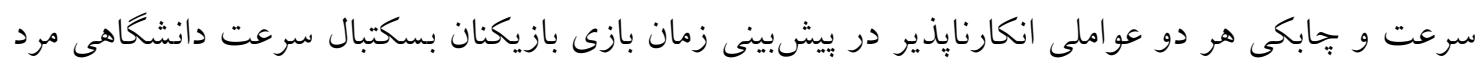
در كروهبندى سطح يك'NCAA كزارش شدهاند (هافمن، 1999). سرعت به طور معمول، ازطريق آزمون

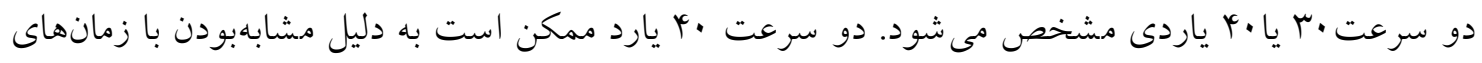

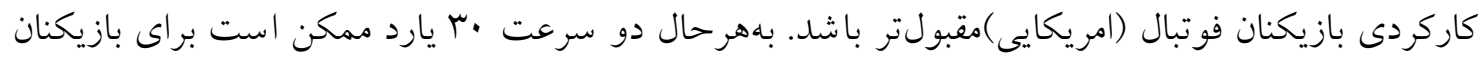

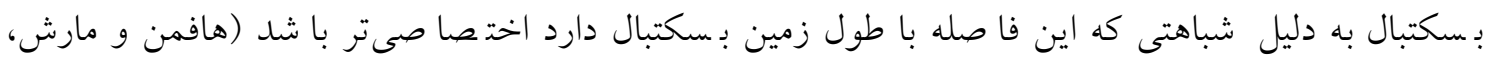

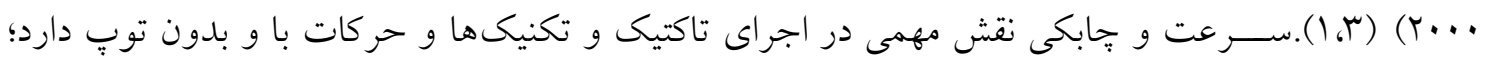

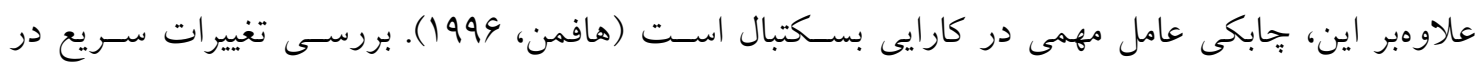

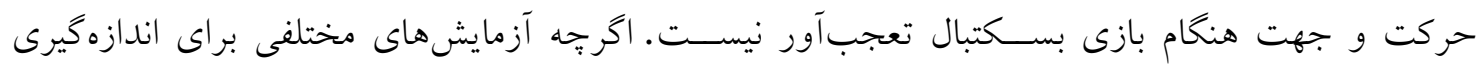

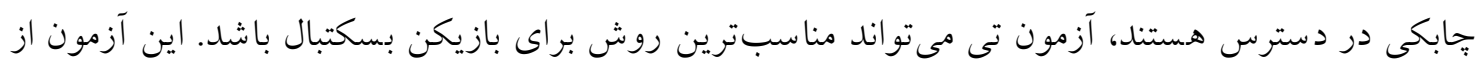

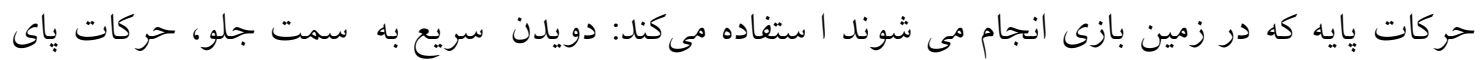

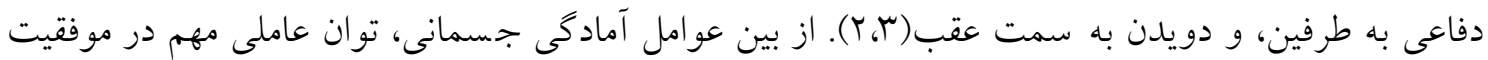

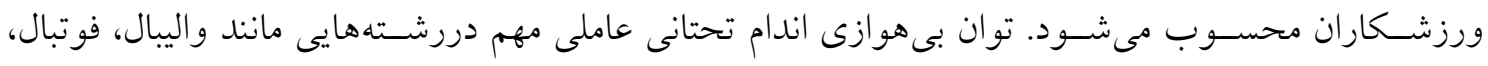

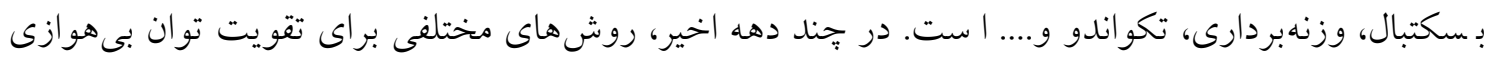

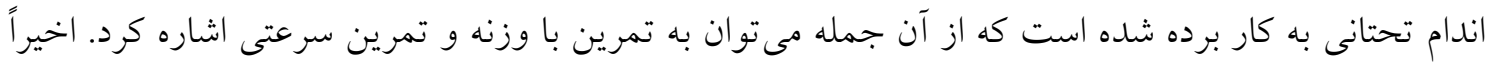

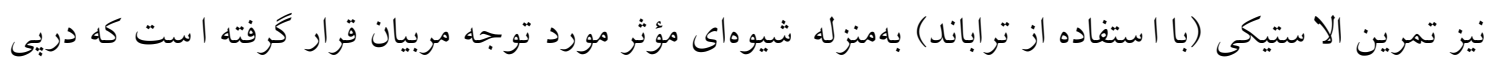

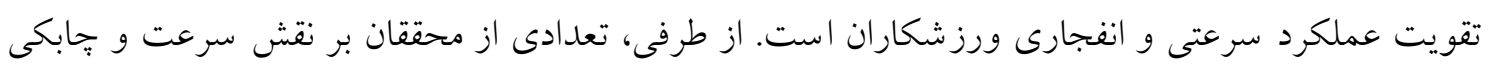

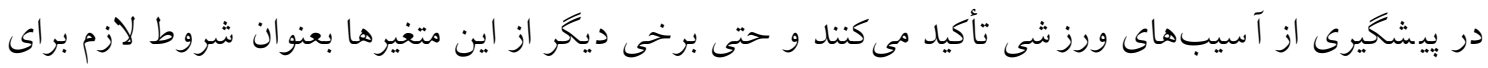

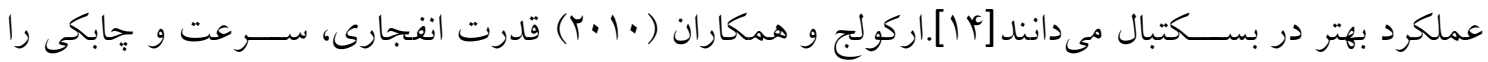

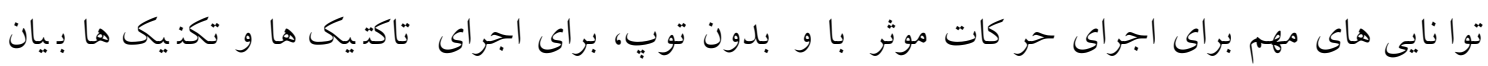

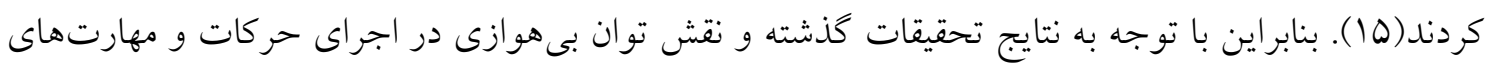

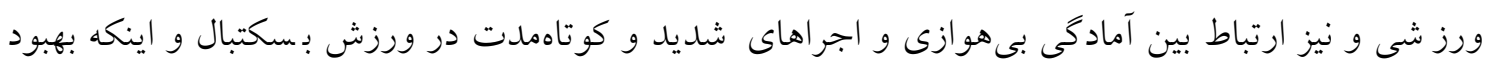

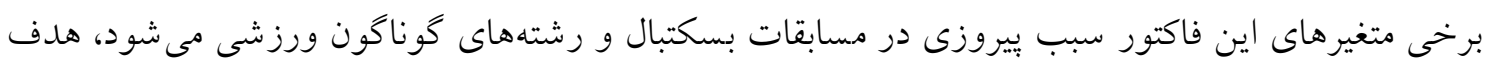

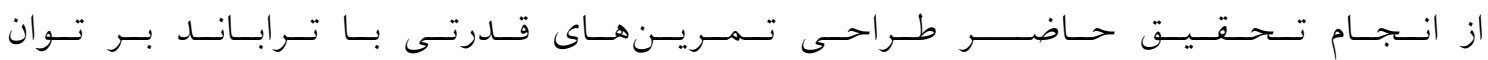
بى هوازى، خابكى و سرعت بازيكنان جوان بسكتبال بود. 
مشاركت كنندكان در تحقيق حاضر را بازيكنان جوان متتخب حاضر در تمرينهاى تيم بسكتبال همدان تشكيل

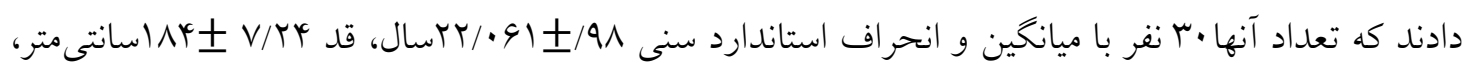
(T) / هVBMI آزمودنى ها فرم رضايتنامه آكاهانه در تحقيق را امضا كردند.

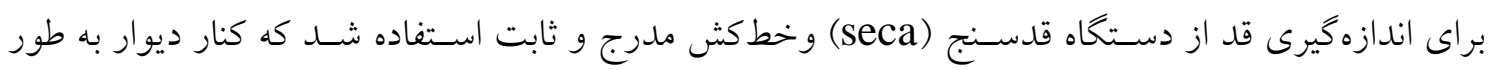
عمودى نصب شده بود. اين خط كش يك تخته افقى دارد كه روى سر قرار مى گيرد. هر مشاركتكننده بدون كفش، يشت به ديوار، به صورت صاف و كشيده مىايستاد؛ بهطورى كه وزن بدن به طور مساوى روى هردو يا تقسيم مى شد، و شانهها در يك سطح قرار مى گرفت و نيز سر و خششمها موازى سطح افق بود. سبس تخته افقى طورى روى سر قرار مى گرفت كه بر كا سه سر مماس بود و با خط كش عمودى زاويه قائم مى ساخت.

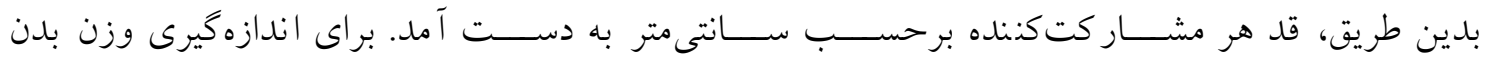
مـشاركت كنند كان از ترازوى ديجيتال وزنكشى (seca) ا ستفاده شد. آزمودنى با ياى برهنه، با كمترين لباس روى ترازو ايستاد و وزن برحسب كيلوگرم اندازه خيرى شد. براى اجراى آزمون يرش سارجنت از آزمودنى خواسته شد كنار ديوارى كه روى آن يكى تخته مدرج برحسب

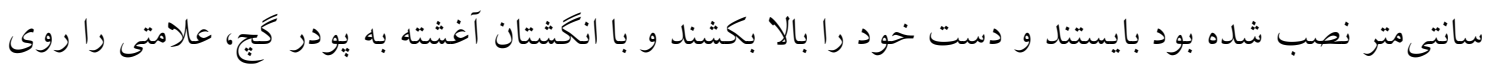

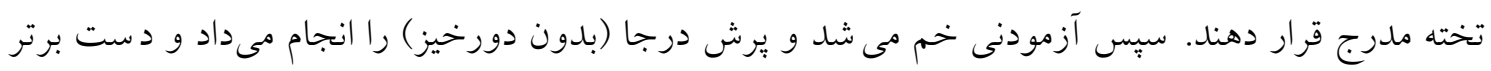

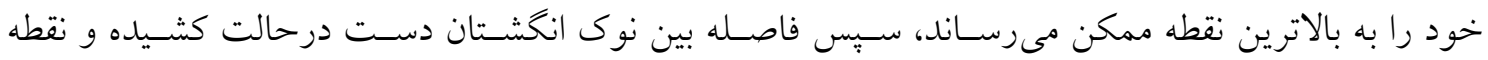

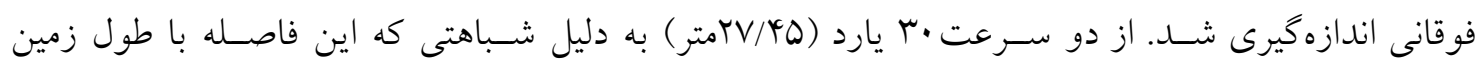

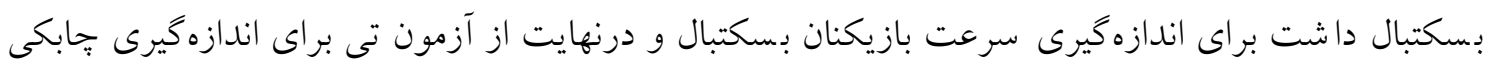

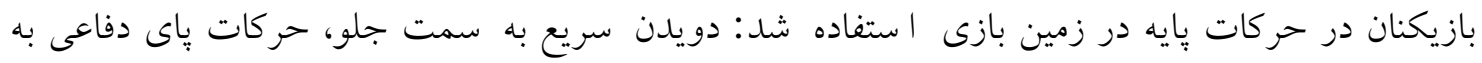
طرفين و دويدن به سمت عقب. 


\begin{tabular}{|c|c|c|c|c|}
\hline زمان استراحت (به ثانيه) & تعداد & تمرينها & رنگ تراباند & $\xi$ \\
\hline ir. & $r_{\text {籸 }}$ & 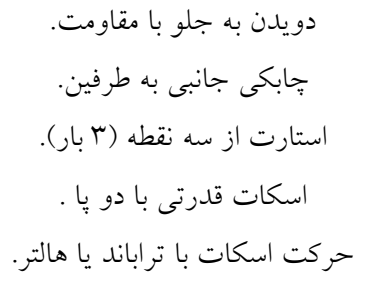 & نقرهاى & $\bar{\xi}$ \\
\hline ir. & 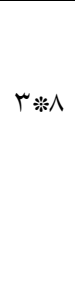 & 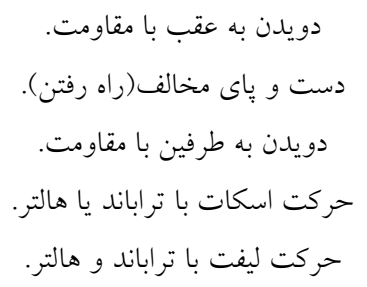 & نقرهاى & $\hat{\xi}$ \\
\hline ir. & $r_{\text {籸 }}$ & 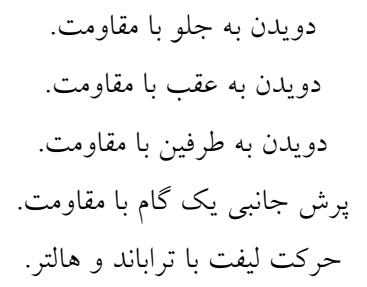 & نقرهاى & $\vec{\xi}$ \\
\hline ir. & $r_{\text {籸 }}$ & 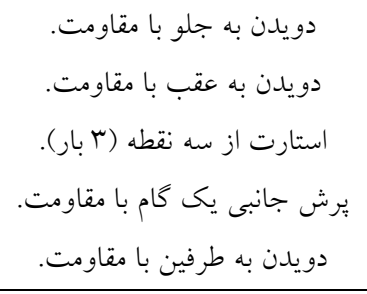 & طلايى & $\vec{\xi}$ \\
\hline Ir. & $r_{\text {籸 }}$ & 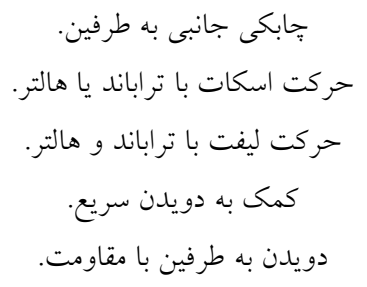 & طلايى & $\begin{array}{l}0 \\
\xi \\
\xi\end{array}$ \\
\hline ir. & $r_{\text {兼人 }}$ & حرك حركت ليفت باست تراباند و هالتر. & طلايى & है. \\
\hline
\end{tabular}

براى توصيف اطلاعات از روش آمار توصيفى (ميانخين و انحراف معيار) و براى بررسى نرمالبودن دادهها از آزمون كلموكروف - اسميرنوف و براى آزمون فرضيههاى تحقيق از آزمونهاى تى (آزمون تى مستقل براى نتايج

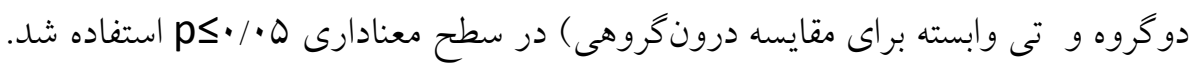


اطلاعات توصيفى آزمودنى ها در جدول آدميق آمده است.

\begin{tabular}{|c|c|c|c|}
\hline انحراف معيار & ميانخين & كروه & \\
\hline $91 / 1$ & $.9 / T Y$ & تجربى & \multirow{2}{*}{ سن (سال) } \\
\hline $1 / 94$ & $r T / \cdot r$ & كنترل & \\
\hline$K M / V$ & $10 / V 9$ & تجربى & \multirow{2}{*}{ وزن (كيلو گرم) } \\
\hline$V / \mathbb{Q} Q$ & $V Q / V T$ & كنترل & \\
\hline$T V / V$ & $1 / T^{4}$ & تجربى & \multirow{2}{*}{ قد (سانتيمتر) } \\
\hline$V / r \Lambda$ & $1 \wedge r$ & كنترل & \\
\hline $9 \mathrm{~V} / \cdot$ & TN/TY & تجربى & \multirow{2}{*}{$(\mathrm{kg} / \mathrm{m} 2) \mathrm{BMI}$} \\
\hline $1 / \cdot r$ & $T r / F q$ & كنترل & \\
\hline
\end{tabular}

نتايج نشان مىدهد كه تمام متغيرها از توزيع طبيعى برخوردارند و متغيرهاى بيشفرض نرمالبودن را براى

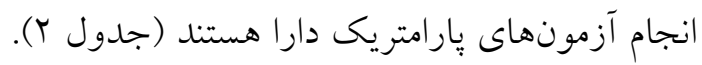

\begin{tabular}{|c|c|c|c|c|c|}
\hline \multicolumn{2}{|c|}{ كروه كنترل } & \multicolumn{2}{|c|}{ كروه تجربى } & \multirow{2}{*}{\multicolumn{2}{|c|}{ متغير ها }} \\
\hline سطح معنى دارى & آماره & سطح معنى & Zآماره & & \\
\hline.$/ 91$ & $\cdot / \mu^{4}$ &.$/ 91$ & $\cdot 109$ & ييش آزمون & برش سارجنت \\
\hline . $/ 94$ & $\cdot / Q r$ &.$/ 49$ & $\cdot / \wedge \Delta$ & ييش آزمون & جابكى \\
\hline.$/ 9 V$ & $\cdot / A V$ & $\cdot / \mathrm{VA}$ &.$/ 90$ & ييش آزمون & سرعت \\
\hline
\end{tabular}

اطلاعات مربوط به ميانخين، دامنه تغييرات، انحراف اسـتاندارد، درجه آزادى و سـطح معنادارى ركوردهاى يرش سارجنت، جابكى و سرعت در دو گروه تجربى و كنترل در بيش آزمون ذشان داد كه تفاوت معنادارى

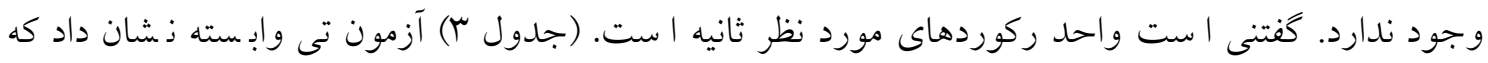

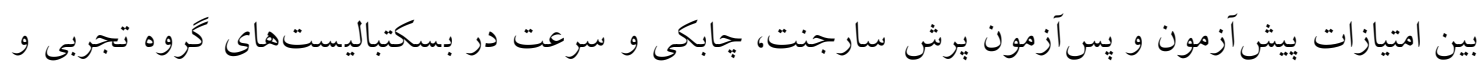

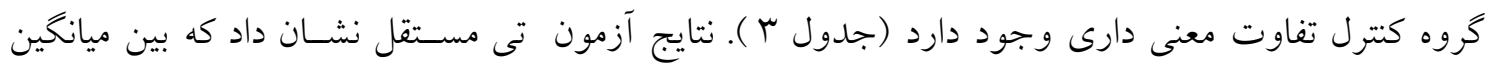

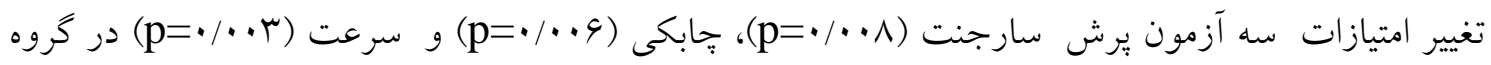

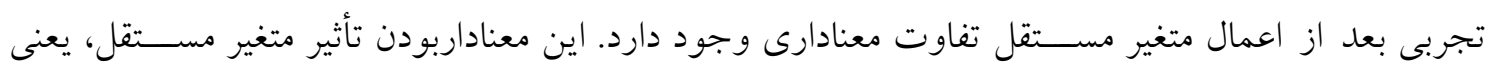


تمر ينات قدرتى با تراباند بر برخى متغيرهاى توان بىهوازى (جابكى، سرعت، يرش عمودى) بسكتباليستهاى جوان را تاييد مى كند (جدول r).

جدول r. آمارههاى مربوط ميانكين تغيير امتيازات سه آزمون در گروه تجربى و كنترل

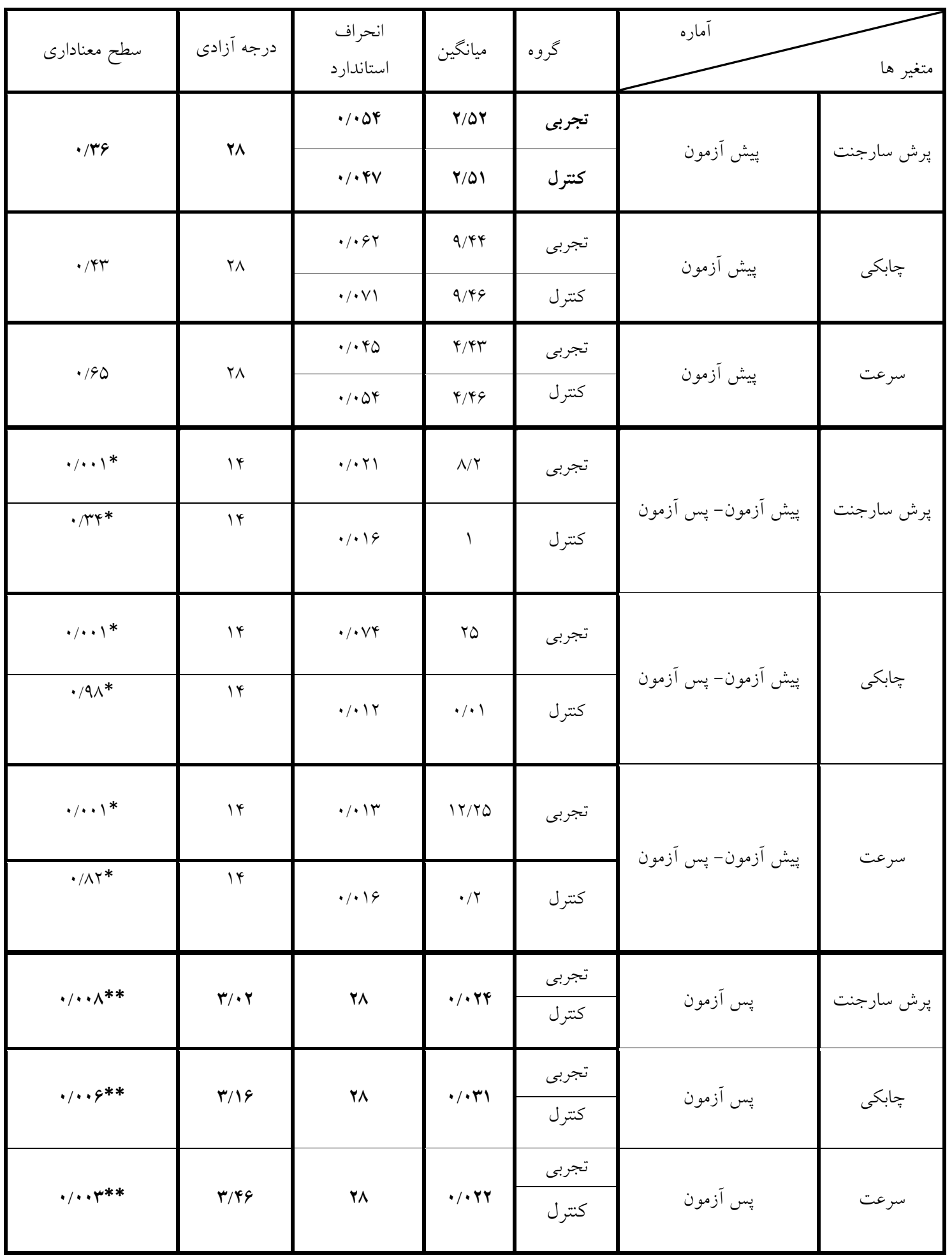

* * اختلاف معنادار بين امتيازاتيش آزمون و پِ آزمون) گروه تجربى و كنترل 米米 الختلاف معنادار بعد از اعمال متغير مستقل 


\section{بحث و نتيجه تيرى}

هدف اين تحقيق بررسسى تأثير تمرين قدرتى با تراباند بر برخى متغيرهاى توان بـىهوازى بسـكتباليستهاى

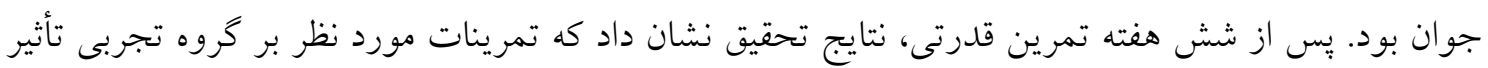

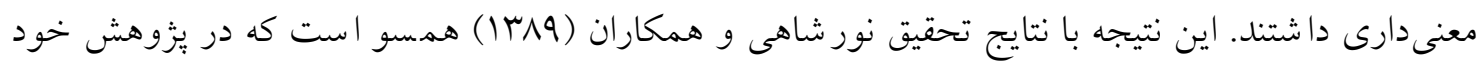

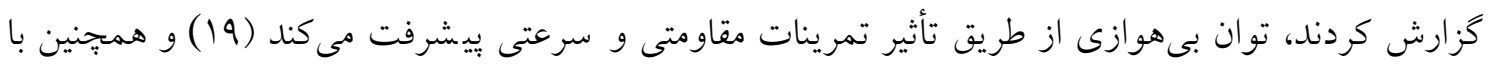

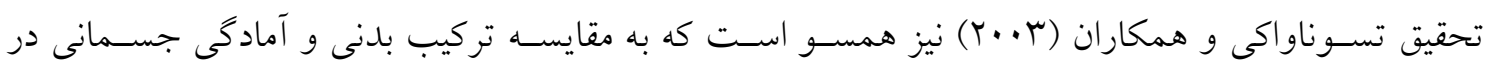

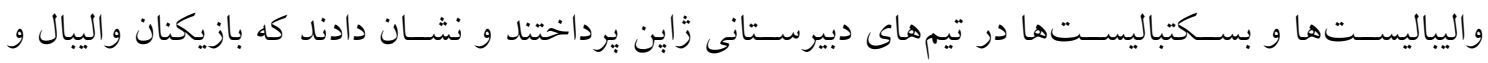
بســكتبال براى ييروزى در مســابقات به ظرفيت هاى بالاى هوازى، بى هوازى و توده بدنى بالا نياز دارند.

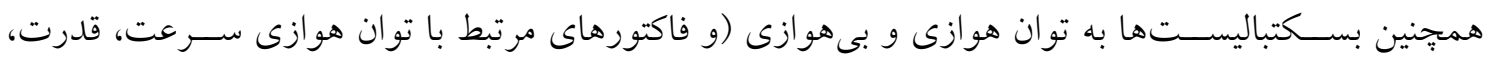

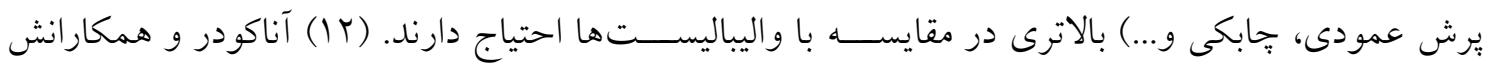

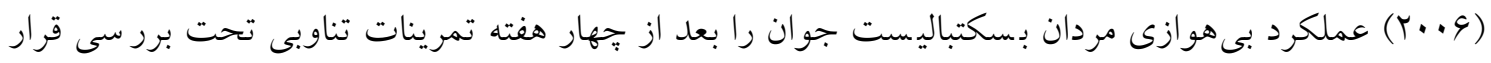

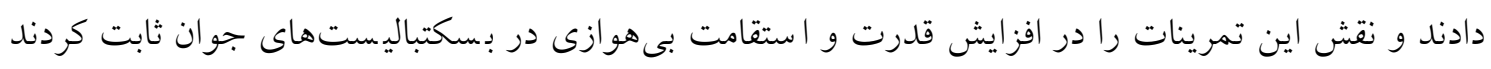

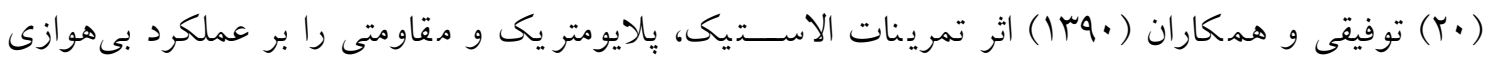

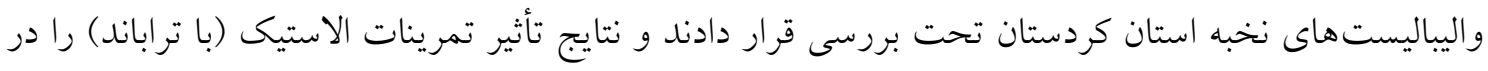

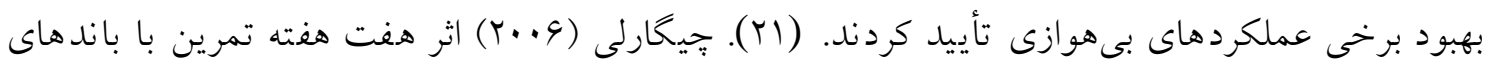
كشى و تمرينات مقاومتى را بر قدرت و توان بالاتنه فوتباليستها برر سى و تاثير مثبت آنرا تأييد كرد (Y (Y).

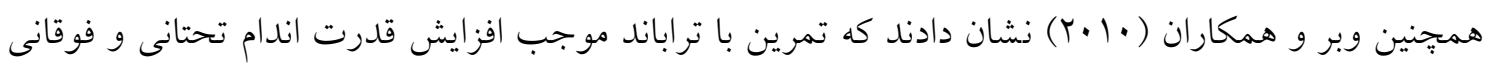

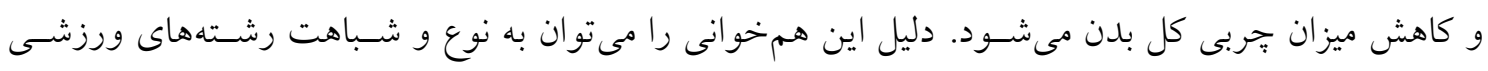

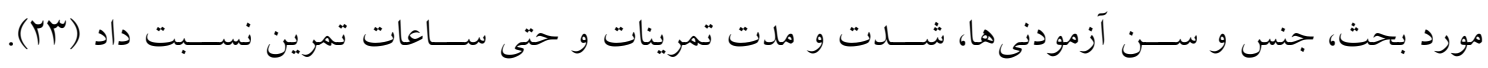
سازو كارهاى مـ سئول تقويت عملكرد بى هوازى در اثر تمرينات سرعتى ممكن ا ست با افزايش توليد نيرو و

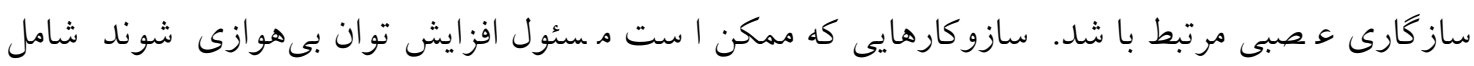

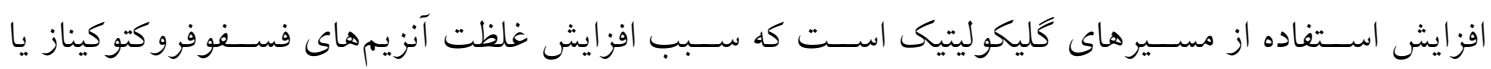
فسفوريلاز مى شود و بدين ترتيب به افزايش نسبى در توليد نيرو و ساز كارى عصبى مىانجامد (YY). افزايش

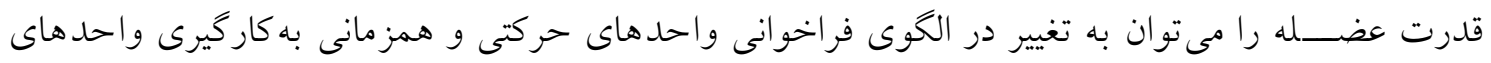

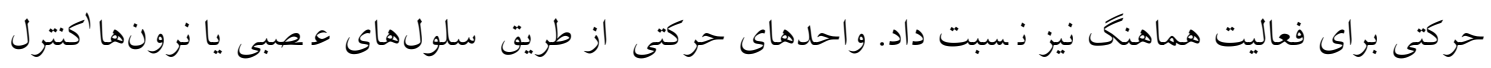

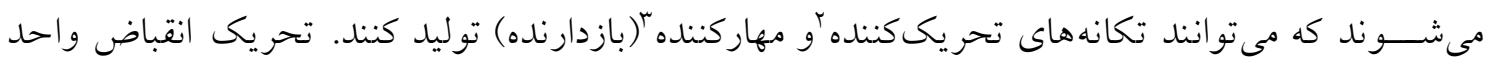
حركتى را موجب مى شــود؛ از سـوى ديخر، مهار از اعمال نيرو توسـطـ عضــلات بيشاز مقدار تحمل بافت

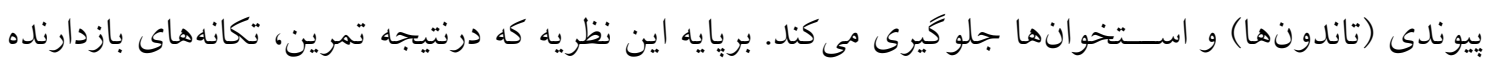

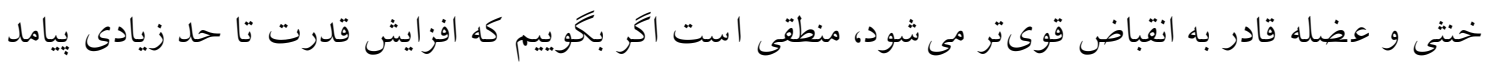




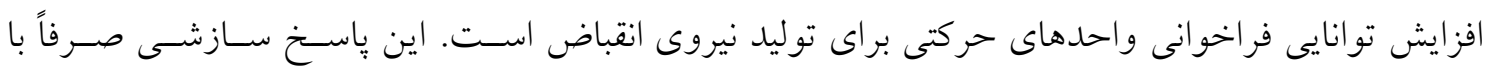

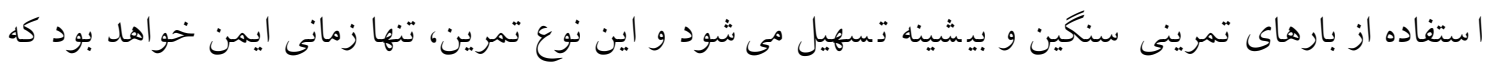
تاندونها با تمرينات شديد ساز كارى بيدا كرده باشند.

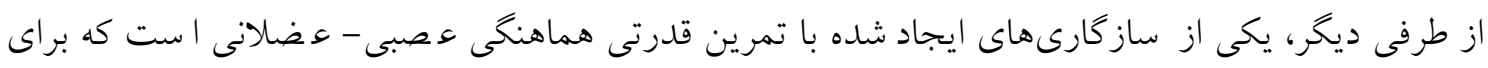

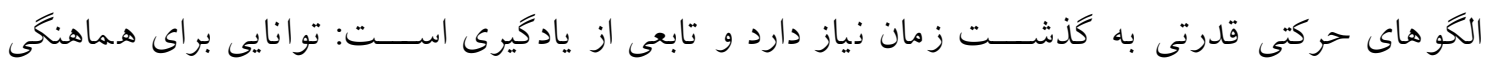

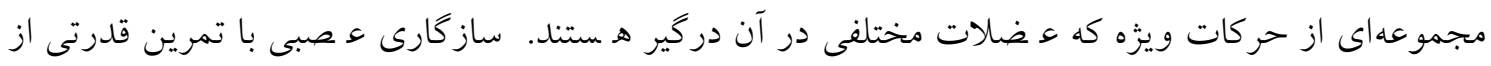

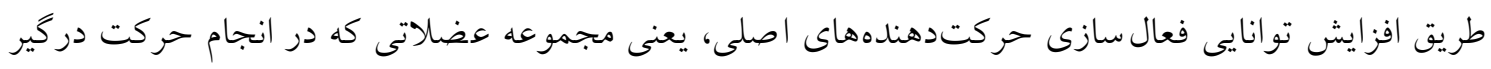

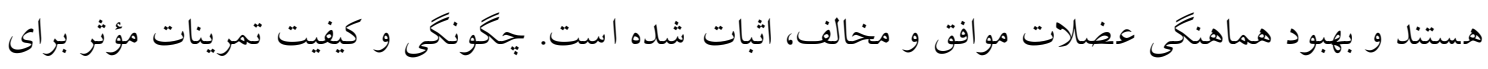

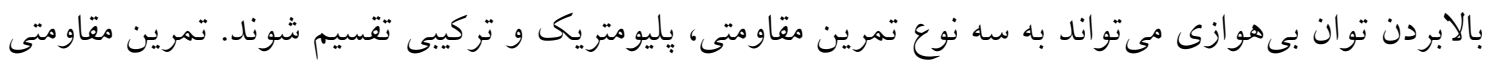

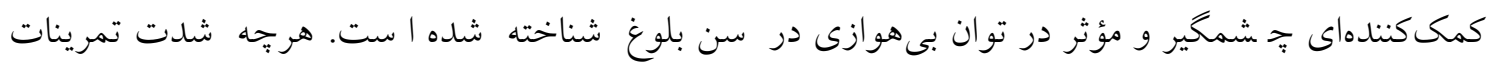

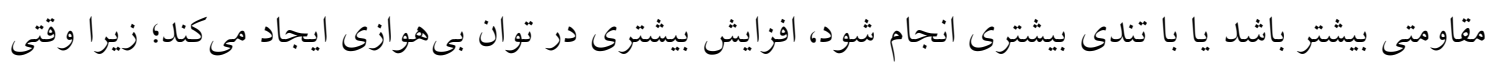

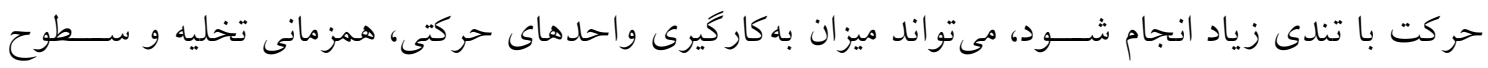

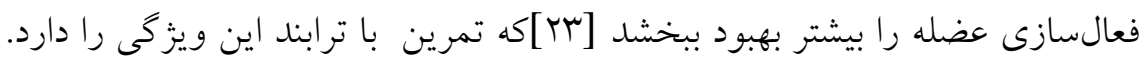

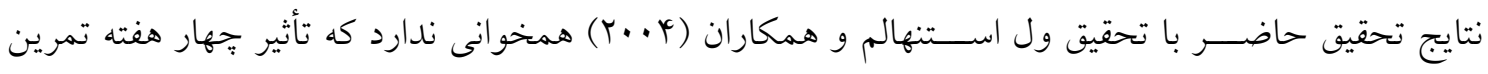

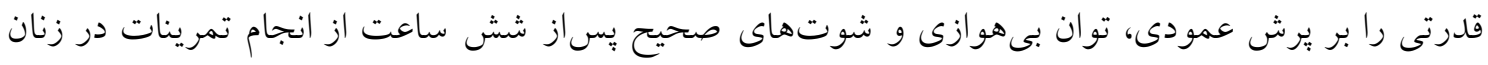

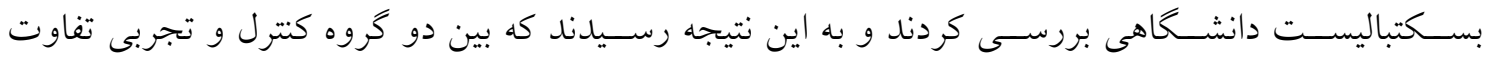

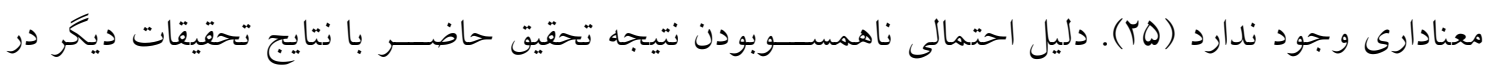

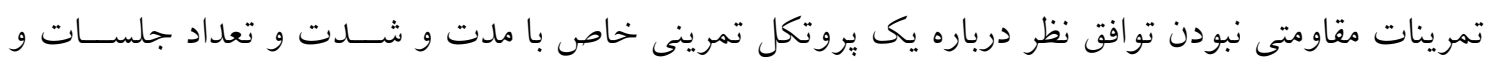

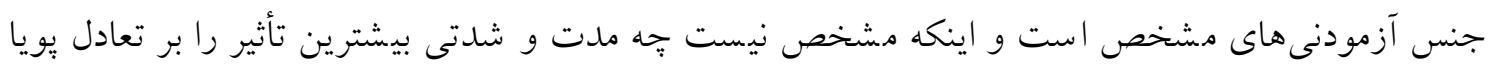

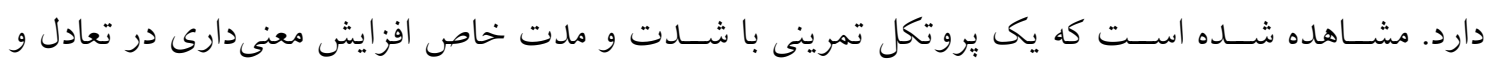

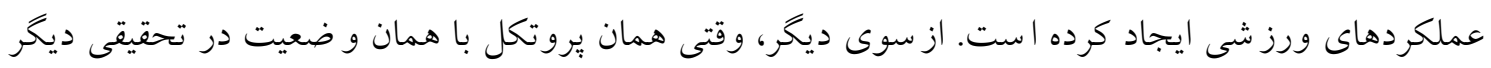

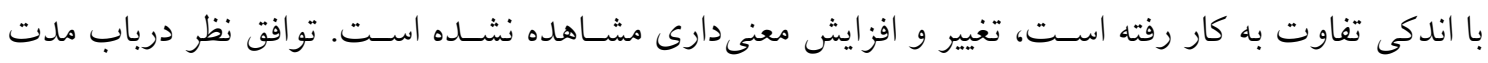

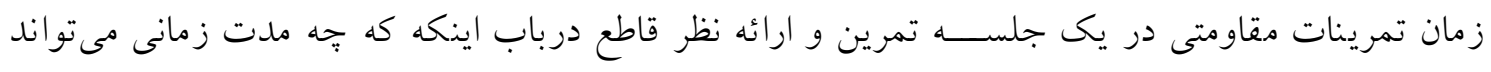

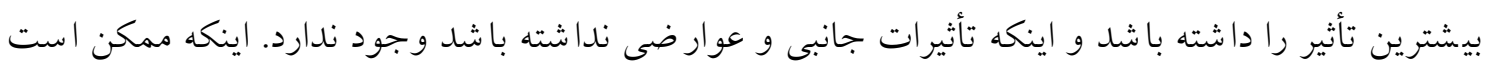

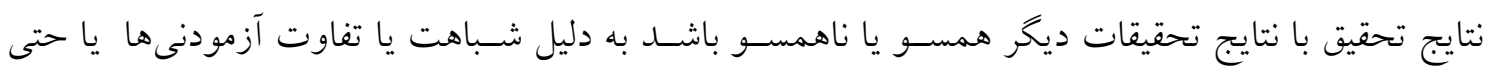

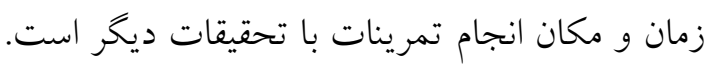

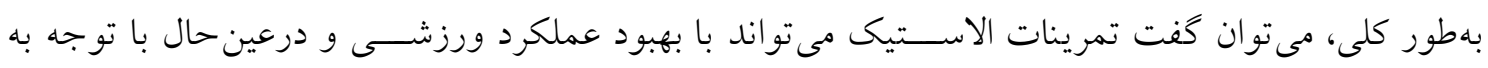

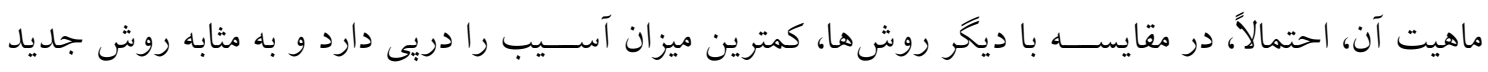

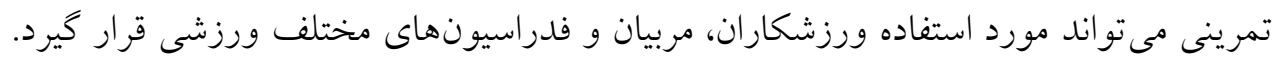


1. Hoffman, J.R., Maresh, C.M. (2000). Physiology of Basketball. In: W.E. Garrett \& D.T. Kirkendall, eds. Exercise and Sport Science. 733-44

2. Hoffman, J.R., Tennenbaum, G., Maresh, C.M., Kraemer, W.J. (1996). Relationship between athletic performance tests and playing time in elite college basketball players. Strength and Conditioning Research.10: 67-71.

r.

4. Meckel, Y., Eliakim, A., Seraev, M., Zaldivar, F., Cooper, D.M., Sagiv, M., Nemet, D. (2009). The effect of a brief sprint interval exercise on growth factors and inflammatory mediators. Strength \& Conditioning Research. 23 (1): 22530

5. Jay. T., Kearney. B. (2000). Measurement and work and power in sport, Exercise and Sport Science, Lippincot Willuom \& Wilking Publishing.

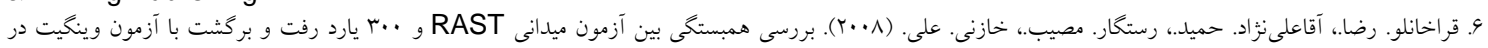

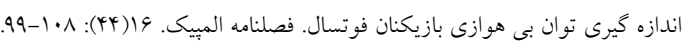

7.Slievert, G., Backus, R.D., Wenger, H.A. (1995). The influence of strength - sprint training sequence on multi-joint power output. Medicine Science in Sports Exercise, Medical Sciences. 27(12): 16-55.

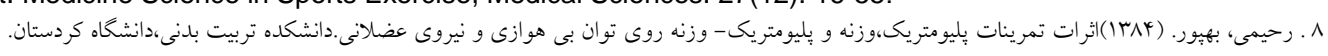

9. Kiapevskal, B. (2001). The effects of sprint (300 m) running on plasma lactate uricacid, creatin kinase, and lactate dehydrogenas in competitive hardlers and untrained men. Sports Sed Shys Fitness. 41(3): 06-31.

10. Carmelo, B., Pekka, L., Paavo, V. K.(1983). A Simple Method for Measurement of Mechanical Power in Jumping. European Journal of Applied Physiolog . 50: 273-82

11. Kasabalis, A., Douda, H., Tokmakidis, S.P. (2005). Relationship between anaerobic power and jumping of selected male volleyball players of different ages. Perceptual and Motor Skills. 100(3): 607-14.

12. Noriaki, T., Yasuaki, T., Kazuhiko, M., Satoshi, M., Kengo, M., Koichi, Y.(2003). Body composition and physical fitness of female volleyball and basketball players of the Japan inter-high school championship teams. Physiol Anthropol and Applied Human Science. 22: 195-201.

13. Schilling, B.K., Stone, M.H. (2000) Stretching: acute effects on strergth and power performance. National Strength and Conditioning Association . 22: 44-7.

14. Delextrat, A., Cohen, D. (2009). Strength, power, speed, and agility of women basketball players according to playing position. Journal of Strength and Conditioning Research. 23(7): 1974-81.

15. Erculj, F., Blas, M., Bracic, M. (2010). Physical demands on young elite European female basketball player's withspecial reference to speed, agility, explosive strength, and take-off power. Strength \& Conditioning Research. 24(11): 2970-78.

16. Phil, P.T. (2005). Strength band training. Human Kinetics. (USA).

17. Kyungmo, H., Mark D.R., Gilbert W.F. (2009). Effects of a 4-week exercise program on balance using elastic tubing as a perturbation force for individuals with a history of ankle sprains. Orthopaedic \& Sports Physical Therapy. 39(4): 24655.

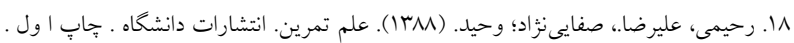

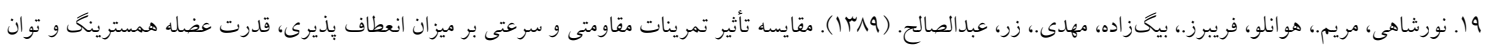

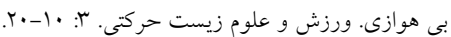

20. Kuder, A., Norkowski, H., Dulnik, K., Skrzec, D. (2006). Anaerobic Performance of Young Female Basketball Players after Interval Training. Exercise Physiology \& Sports Medicine. 12 (2): 103-14.

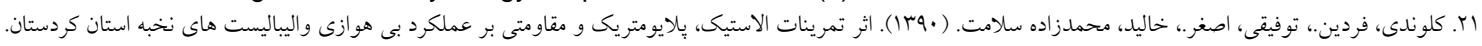

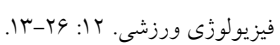

22. Ghigiarelli .J. (2006). The effect of a seven week heavy elastic band and weighted chain program on upper body strength and upper body power in sampel of division 1-AA football players. Strength \& Conditioning Research. 23(3): 756-64.

23. Webber, S.c., Porter, M.M. (2010). Effect of ankle power training on movement time in mobility-impaired older women. American college of sport medicine. Medicine \& Science in Sports \& Exercise. 42(7): 1233-40.

24. Tanya, A., Miszko, M., Elaine, C., Jill, M.S., Carlton, J.C., Subodh, K. (2003). Effect of strength and power training on physical function in community-dwelling older adults. Gerontology: Medical Sciences. 58 (2): 171-5.

25. Mandy, T., Woolstenhulme, B., Kerbs, B., Philip, E.A. (2004). Vertical jump, anaerobic power, and shooting accuracy are not altered 6 hours after strength training in colleglate women basketball players. Strength and Conditioning Research.18(3): 422-5. 


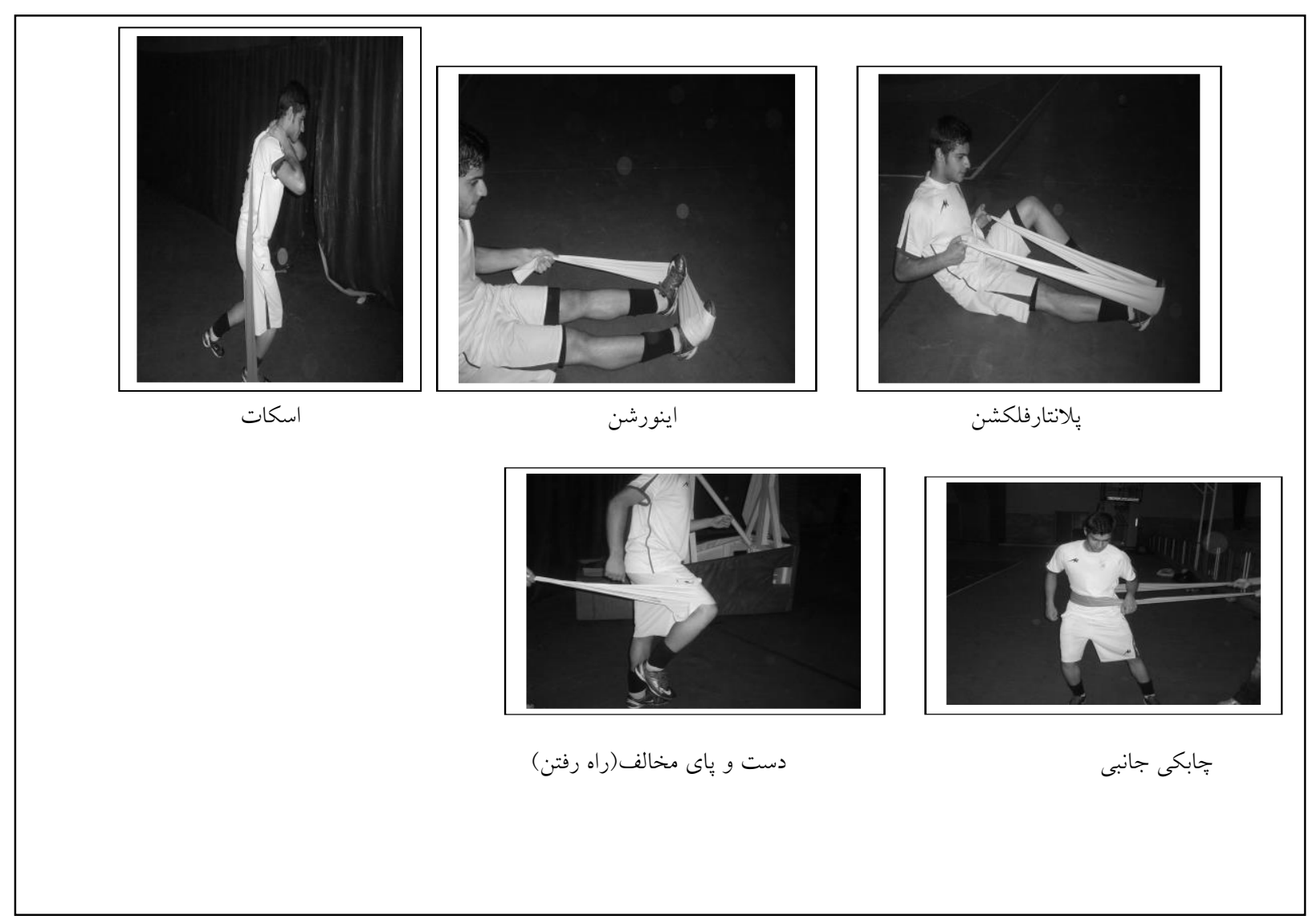

